$\begin{array}{lll}\text { KULTURA } & \begin{array}{l}\text { POLSKA A KADEMIA NAUK } \\ \text { KOMITET SOCJOLOGII }\end{array} & \text { ISSN 0023-5172 } \\ \text { i } & \begin{array}{l}\text { INSTYT TT STIÓW POLITYCZNYCH } \\ \text { SPOLECZENSTWO }\end{array} & \\ \text { 2017, nr } 2 \quad \text { ŚWIATY SPOEECZNE SPORTU } & \end{array}$

ZBIGNIEW DZIUBIŃSKI, NATALIA ORGANISTA, ZUZANNA MAZUR Akademia Wychowania Fizycznego w Warszawie

\title{
O MĘSKOŚCI KONSTRUOWANEJ MEDIALNIE: ZARYS ZAGADNIEŃ TEORETYCZNYCH I PRZYKŁAD ANALIZY EMPIRYCZNEJ*
}

Przedmiotem tych rozważań będzie przede wszystkim władza, jaką mają media w zakresie nadawania znaczeń i reprodukowania treści na temat kobiecości i męskości poprzez sport. Trzeba pamiętać o możliwym zniuansowaniu wpływu treści medialnych na odbiorców (możliwość odczytań peryferyjnych i alternatywnych), jednak obecnie media i sport, wzajemnie od siebie zależne, składają się na mediasport — kompleks narracji, która zasięgiem i siłą oddziaływania przerasta sam sport i wyniki sportowej rywalizacji (Hall 1987; McQuail 2007; Wenner 2015).

\section{SOCJOLOGICZNE TEORIE KONSTRUOWANIA MĘSKOŚCI W SPORCIE: REAWYN CONNELL I ERIC ANDERSON}

Socjologia sportu jest stosunkowo młodą subdyscypliną socjologii. Również od niedawna w badaniach społecznych nad sportem stosuje się kategorię płci kulturowej. Sięga się wówczas zazwyczaj do teorii Reawyn Connell. Australijska badaczka zwróciła uwagę na to, że jeżeli chcemy walczyć z nierównością płci, to musimy lepiej zrozumieć relacje między kobiecością a męskością. Innymi słowy, powinien zostać przeanalizowany sposób konstruowania dominują-

Adres do korespondencji: natalia.organista@gmail.com

* Badania zrealizowano w ramach projektu statutowego AWF Warszawa, DM-35: „Nierówności płciowe w sporcie na przykładzie treści artykułów prasowych Gazety Wyborczej w latach 2010$-2013 "$. 
cej wersji męskości. Connell $(2001,2000,1998)$ stworzyła hierarchię wzorów męskości i kobiecości. Dominującą pozycję w kulturze, według niej, ma męskość hegemoniczna, którą cechuje wysoki status społeczny, fizyczna sprawność oraz heteroseksualność. Należy jednak pamiętać, że w poszczególnych społeczeństwach zawsze występują różne męskości oraz że są one zmienne historycznie. Ponadto męskość i kobiecość zawsze są do siebie relacyjnie odniesione.

Wzorce relacji płci podtrzymują cztery struktury relacji władzy w społeczeństwie (sfera symboliczna, prywatna, pracy oraz władzy). Wzajemne powiązanie tych struktur realizuje się poprzez praktyki cielesne. Fizyczność jest podstawowym źródłem interpretowania kobiecości i męskości, a sport to jedna z instytucji społecznych, w których najłatwiej można zaobserwować rolę ciała w podtrzymywaniu relacji między płciami. Siła, wytrzymałość, perfekcyjne wytrenowanie składają się na tradycyjne spojrzenie na męskość. Kobiecość natomiast to podążanie za kulturowym ideałem piękna, bierność, podległość oraz empatia. Co więcej, wizerunki kobiet w sporcie podlegają ambiwalentnym ocenom kulturowym. Siła, wytrzymałość i fizyczna sprawność, konieczne do odniesienia sukcesu w sporcie, nie mieszczą się bowiem w kulturowym ideale kobiecości. Dlatego medialne wizerunki kobiet w sporcie mogą mieć wywrotowe znaczenie dla patriarchalnej kultury (zob. Messner 1994). Zwraca się też uwagę, iż kobiecość w sporcie jest marginalizowana i trywializowana ze względu na ocenianie kobiet jedynie poprzez ich wygląd zewnętrzny.

Relacyjne spojrzenie na kategorię kobiecości i męskości pozwoliło na analizę wzorów tworzonych przez współczesny sport. Z feministycznej perspektywy widać, że przenosi on wiele patriarchalnych norm i wartości. Głównym zadaniem stojącym przed instytucją sportu - takiego, jaki dzisiaj znamy - poza celem komercyjnym, jest reprodukowanie określonej wizji męskości (Messner, Dworkin 2002). Connell $(2000,2001)$ podkreśla, że sport służy reprodukowaniu męskości hegemonicznej, marginalizowaniu zaś innych rodzajów męskości. W ten sposób sport, uważany za jedną z najbardziej „męskich” instytucji społecznych, przyczynia się do utrzymywania hierarchii między płciami (Messner, Sabo 1994; Messner 1992). Za „rdzeń” męskości uznane są sporty zespołowe, które charakteryzuje dominacja jednej drużyny nad drugą, konieczność wypracowania podległości wobec lidera, zaciętości, siły fizycznej i wytrzymałości. Od XIX wieku sport jest głównym wehikułem socjalizacyjnym dla chłopców — służy do „budowania charakteru” mężczyzn.

Rolę sportu w tworzeniu się porządku płci, kształtowaniu męskości i relacji władzy w społeczeństwie unaoczniły analizy kształtowania się instytucji sportu w XIX wieku w społeczeństwach anglosaskich (Whitson 1989; Kidd 1989; Crosset 1989; Kimmel 1989). Sport pomagał i pomaga gruntować symboliczną i kulturową przewagę męskości w społeczeństwie. Również kibicowanie, zwłaszcza w sportach drużynowych, powiązane jest z kultywowaniem określonej formy męskości. Homospołeczność jest często przywoływanym pojęciem 
odnoszącym się do tych przestrzeni, w których mężczyźni mogą podtrzymywać relacje między sobą bez narażania się na uwagi o nadmiernej bliskości i homoseksualizmie (różnego rodzaju bractwa czy fankluby) (Jakubowska 2013). Poczucie przynależności do większej grupy, wyższości czy dumy to niektóre z doznań podtrzymujących męskie zainteresowanie sportem. Wspólnotę tę umacniają rytuały przejścia (Kimmell 2009; Messner, de Oca 2005). Duma jest zazwyczaj kolektywizowana przez rzesze fanów sportów zespołowych, a zatem sportowczynie - rozpoznawane zwykle w sportach indywidualnych - nie są „nośnikiem” wartości narodowych (Lippe 2002). Dlatego utrwaliło się przekonanie o sporcie jako „męskiej i świeckiej formie religii” (Anderson 2009).

Obecnie w analizach dotyczących konstruowania męskości przez sport dostrzega się, że bywa on dla chłopców, przyszłych zawodowych sportowców, zajęciem opresywnym. Socjalizacja do sportu pociagga za sobą naukę działań przemocowych, alienacji własnego ciała, traktowania innych przedmiotowo (Hasbrook, Harris 2006). Wejście w instytucję sportu uczy warunkowego poczucia własnej wartości. Wzmacnianie więzi następuje tylko wtedy, gdy osiągnie się znaczące wyniki w danej dyscyplinie sportu (Messner 1992). Kolejne etapy zaangażowania w sport można tłumaczyć rozwijaniem męskości i chęcią uzyskania wysokiego statusu w grupie rówieśniczej. Przygotowująca przyszłych, profesjonalnych sportowców instytucja sportu jest bardzo zhierarchizowana i nastawiona na współzawodnictwo. Chłopcy szybko zaczynają rozumieć, że uznanie ze strony ojców (to oni głównie kierują chłopców w stronę sportu), trenerów czy grupy rówieśniczej trwa tak długo, jak długo są oni w stanie być bardzo dobrymi w danej dyscyplinie (Messner 1992).

Konsekwencją praktyk konstruujących współczesnych sportowców jest szczególny sposób odnoszenia się do swojego ciała. Badania Messnera (1992) potwierdzają tezę Connell, że ciało odgrywa główną rolę w konstruowaniu męskości. Sportowcy są zorientowani na osiąganie celów, w innych widzą rywali, których trzeba pokonać czy zmanipulować. Skrajnym przykładem takiej racjonalizacji jest postrzeganie swojego ciała jako broni czy maszyny, której się używa. Ból czy problemy emocjonalne związane $z$ takim traktowaniem samego siebie są zagłuszane albo oceniane jako nieistotne. Takie postępowanie ze swym ciałem - jako narzędziem - często prowadzi do przemocy wobec innych i ostatecznie wobec siebie samych. Stąd twierdzenie, że ból jest zasadą organizującą instytucję sportu w dużo większym stopniu niż przyjemność (Messner, Sabo 1994). Ból jest męski, przyjemność nie. W tym sensie zużycie ciała nie jest indywidualną sprawą, lecz kwestią oddziaływania systemu ${ }^{1}$.

\footnotetext{
${ }^{1}$ Przykładem ilustrującym tę sytuację jest próba wyciszenia wyników badań pokazujących związek między schorzeniami neurologicznymi a częstymi wstrząśnieniami mózgu u zawodników futbolu amerykańskiego czy niedopuszczenie do emisji filmu dokumentalnego na ten temat (League of Denial). W 2013 roku 4,5 tys. byłych zawodników złożyło pozew przeciwko National Football League (NFL) o odszkodowanie za utracone zdrowie, argumentując, że zarządzający ligą wiedzieli
} 
Sposób konstruowana męskości w sporcie Michael Kaufman (1987) nazywa triadą męskiej przemocy, na którą składa się: przemoc wobec kobiet (mizoginiczne żarty, tępienie empatii wobec kobiet, przemoc domowa i seksualna), przemoc wobec innych mężczyzn (konstruowanie innego jako wroga), przemoc wobec samych siebie (ryzykowne zachowania, negowanie sygnałów ciała). W zachowania przemocowe najczęściej zaangażowani są mężczyźni uczestniczący w sportach sytuujących się w instytucjonalnym centrum. W Stanach Zjednoczonych są to: futbol amerykański, koszykówka, baseball, hokej na lodzie.

Teoria Connell - ukazująca, w jaki sposób męskość hegemoniczna jest odtwarzana w sporcie - nie jest wolna od ograniczeń. Przede wszystkim odnosi się do sytuacji w sporcie zawodowym, a pomija rekreacyjny sport dzieci, młodzieży i dorosłych. Należy też zwrócić uwagę, że badania nad męskością w sporcie $\mathrm{w}$ większości dotyczyły sportów zespołowych. W mniej zinstytucjonalizowanych dyscyplinach sportu, jak kulturystyka czy pływanie, obserwuje się szersze spektrum zachowań, od mizoginicznych do egalitarnych. Badanie „peryferii” sportu może zatem ujawnić alternatywne sposoby tworzenia relacji płci w sporcie (McKay, Messner, Sabo 2000, s. 8). Ponadto teoria intersekcjonalności podpowiada, że uprzywilejowanie z powodu jednej kategorii społecznej (płeć) może współwystępować z dyskryminacją z powodu innej kategorii (np. etniczność, niepełnosprawność) (zob. Coston, Kimmel 2012). Należy brać pod uwagę także to, że opisywana teoria Connell odnosi się do pewnego momentu historycznego.

Eric Anderson (2005) proponuje inkluzyjną teorię męskości jako lepiej opisującą obecny stan rzeczy. Uważa, iż teoria Connell nie chwyta zmian, które dokonały się w ostatnim ćwierćwieczu i polegają przede wszystkim na większej otwartości na homoseksualizm. W związku z tym, według Andersona, nie możemy już mówić o bezrefleksyjnym łączeniu sportów drużynowych i homofobii i, co się z tym wiąże, że homofobia jest oparta na prostym fakcie bycia młodym mężczyzną. Stygmat uwarunkowany homoseksualizmem ma mniejsze znaczenie, co powoduje, że erozji ulega hierarchiczna stratyfikacja męskości. Dopuszcza się istnienie wielu rodzajów męskości, bez dominacji jednego typu nad drugim (Anderson 2012).

Wyniki współczesnych badań pokazały (Adams, Anderson, McCormack 2010), że zarówno trenerzy, jak i zawodnicy nie tylko konstruują i ustanawiają dominujący dyskurs męskości, lecz że w ich zachowaniach daje znać o so-

o niebezpieczeństwie rozwinięcia się schorzeń neurologicznych u zawodników często doznających wstrząśnienia mózgu, ale nic z tym faktem nie zrobili. Liga dopuściła się tym samym zaniedbania i oszustwa. Takie postępowanie przypisywano „kulturze twardości”, którą NFL aktywnie wspierała (Guccione 2014; Gove 2012). Ostatecznie NFL zgodziła się wypłacić byłym zawodnikom 735 milionów dolarów. Część sumy miała zostać przekazała również na badania naukowe nad zaburzeniami neurologicznymi. Po podaniu w wątpliwość, czy taka kwota odszkodowania będzie wystarczająca, NLF przystało na ugodę bez ustanawiania górnej wysokości odszkodowań. 
bie również dyskurs podważający dominującą wersję męskości, co przejawia się w subtelnych, niekonformistycznych zachowaniach. Zawodnicy akceptują pewną dozę męskości hegemonicznej podczas pracy na boisku, ale potrafią się wobec niej zdystansować poza światem sportu. Starają się też unikać przemocy i agresji. Obserwacji tego typu nie można generalizować, potrzebne są kolejne badania, na innych drużynach o różnym poziomie sportowym i edukacyjnym. Być może dyskurs dominującej męskości reprodukujący się poprzez zinstytucjonalizowane centrum sportu z jakichś powodów nie jest już przekaźnikiem określonych wartości poza świat sportu.

Istnieją badania nad seksualnością, męskością i sportem, które pokazały, że stosunek do homoseksualności uległ dużej zmianie w kierunku większego przyzwolenia na „kobiece” postępowanie czy akceptację faktu homoseksualizmu kolegi z zespołu (Anderson 2011, 2012; Adams 2011), ale jest też wiele dowodów na to, że utrzymują się sztywne podziały na sporty odpowiednie dla mężczyzn oraz kobiet. Kobiety w sportach uważanych za męskie i mężczyźni w sportach uważanych za kobiece muszą negocjować swoją tożsamość, znajdować sposób na określenie swojej płciowości, a także często mierzyć się z wrogimi postawami, stygmatyzacją oraz przemocą (zob. Chimot, Louveau 2010; Grindstaff, West 2006).

\section{PRZEKAZY MEDIALNE NA TEMAT SPORTU MĘŻCZYZN}

Z uwagi na znaczenie sportu dla podtrzymywania kategorii męskości i kobiecości sportowe przekazy medialne mogą być uważane za papierek lakmusowy stanu relacji między tymi kategoriami. Dotychczasowe analizy ujawniały znaczące różnice $\mathrm{w}$ sposobach prezentowania sportu kobiet i mężczyzn. Sport kobiet był marginalizowany, co znajdowało wyraz zarówno w ilości miejsca i czasu antenowego poświęcanego temu tematowi, jak i w sposobie opisu (Messner, Cooky 2010; Haris, Clayton 2002; Capranica i in. 2005; Bishop 2003). Kapitał kulturowy sportu kobiet w świetle przekazów medialnych jest znacząco mniejszy niż mężczyzn (Boyle, Haynes 2009). Przekazy te koncentrują się na wyglądzie fizycznym zawodniczek, ich życiu pozasportowym, związkach prywatnych. Taki sposób opisu trywializuje ich osiągnięcia. Powstaje wrażenie, iż sport kobiet jest gorszą wersją sportu mężczyzn, który uchodzi za wzór.

Inne są opisy sportu mężczyzn. W warstwie ilościowej zwraca uwagę, że najczęściej się pisze o sportach kontaktowych i kolizyjnych oraz drużynowych (Jones, Greer 2011; Theberge, Cronk 1994). Dyscypliny takie jak boks, hokej na lodzie czy piłka nożna są zdominowane przez mężczyzn, wymagają pewnej dozy przemocy czy agresji oraz symbolizują siłę lub zaciętość. Towarzyszy im metafora ciała jako broni czy maszyny do walki (Boyle, Haynes 2009). Ponieważ sport „naładowany” jest wartościami uważanymi za męskie, to skoncentrowanie uwagi mediów na ich wysiłkach wzmacnia przekonanie, że sport wydobywa 
najlepsze cechy męskości. Siła fizyczna, wytrzymałość i determinacja są podkreślane, co kształtuje przekonanie o męskiej wielkości (Boyle, Haynes 2009). Podobnie jak waleczność i nieustępliwość powiązana z negowaniem bólu i dochodzeniem do kresu swoich możliwości.

W przekazach sportowych akcentuje się również atletyzm mężczyzn, ich muskulaturę i nadzwyczajne możliwości fizyczne. Stroje zawodników, zwłaszcza w dyscyplinach kolizyjnych, wywołują wrażenie wielkości mężczyzn. Ochraniacze na większość części ciała (kask na głowę, ochraniacze na nogi, szczękę, kark lub kolana) przywołują wizerunki uzbrojonych żołnierzy idących na wojnę. Wszystko to w warstwie wizualnej przyczynia się do odtwarzania męskości hegemonicznej. Przedstawienia cielesności sportowców w mediach są nadnaturalne, przekraczają fizyczne ograniczenia (Sabo, Jansen 1998). Akcentuje się również brawurowe zachowania sportowców, wyjątkowo nieustraszone ataki danej drużyny, aby przedstawiać sportowców jako wyjątkowo odważnych, ambitnych i nastawionych na rywalizację (Boyle, Haynes 2009). Kontuzje są wykorzystywane do pokazania determinacji i siły zawodników. Częste powtórki z brutalnych starć między zawodnikami, oznaki bólu na ich twarzach, mają wysyłać komunikat o odporności na ból, wytrzymałości. Kreślą wizerunek „twardego mężczyzny”. Kontuzje są pokazywane jak rozrywka i stanowią ważny element dodający dramaturgii spektaklowi telewizyjnemu. Powolne ujęcia dają szansę komentatorom na omówienie zdarzenia, a widzom na dokładne jego zapamiętanie. Symbolizują poświęcenie, twardość zawodników.

Media sportowe faworyzują tych, którzy przezwyciężyli ból i wrócili do gry, kreują ich na bohaterów. Zawodnicy czują presję i tłumią oznaki bólu, nawet jeżeli kontuzja może mieć dla ich zdrowia i karier fatalne konsekwencje ${ }^{2}$. Raczej nie znajdujemy tego w opisach sportu kobiet. Doświadczenie kontuzji i walka z nim może mieć zatem charakter płciowy (Sabo, Jansen 1998). Powagę sportu i wysiłek z nim związany oddają metafory wojenne, najczęstszy element komentowania widowisk sportowych. Sport zastępuje obecnie doświadczenie wojny w społeczeństwach patriarchalnych. Sportowe metafory konceptualizują doświadczenia wojny a metafory wojenne odsyłają zarówno do tradycyjnej wizji męskości, jak i do walki w sporcie (Nadelhaft 1993). Język sportu odtwarza prymat mężczyzn w społeczeństwie. Ponadto przekazy sportowe są bardzo stylizowane, melodramatyczne i pełne odniesień do słynnych bitew oraz postaci historycznych (Sabo, Jansen 1998).

Sportowcy w mediach od zawsze byli przedstawiani jako bohaterzy, ale jak zwraca uwagę Leah Berg (2002) - zapośredniczenie sportu przez me-

\footnotetext{
2 Wskazuje się w tym kontekście na „zasadę bólu” (pain principle), czyli przeświadczenie, że ból i cierpienie są nieuniknione, ale ostatecznie prowadzą do zwiększenia wytrzymałości, budowania charakteru danej osoby oraz jej wartości moralnej. Myślenie takie ma mieć swoje korzenie w chrześcijaństwie (Messner, Sabo 1994).
} 
dia zmieniło sposób opisywania bohaterstwa. Tak jak media komercyjne przyczyniły się do zmiany postrzegania sportu ( $z$ amatorskiej, rekreacyjnej działalności przekształcił się on w zorientowany na widza biznes zapośredniczony przez technologię), tak kapitał oraz sponsorzy wpłynęli na sposób narracji o gwiazdach sportu. Do niedawna sportowcy byli bohaterami ze względu na wyśmienite rezultaty, odpowiedzialność społeczną i wartości moralne. Obecnie są również celebrytami, a media kładą nacisk na dominującą kulturowo formę męskości, co w znacznej mierze wyklucza kobiety ze sfery gwiazdorstwa sportowego (Berg 1998). Mężczyźni używają oznak statusu bohatera do celów komercyjnych (głównie reklamy), co zwiększa jeszcze ich udział $\mathrm{w}$ mediach. Jednak nie tylko sportowcy zależą od mediów i biznesu, media potrzebują bowiem sportowców jako nośników treści rozrywkowej, ich osobowości i indywidualności, które pośredniczą w przekazywaniu informacji.

Gwiazdorstwo sportowe stało się popularną formą produkcji medialnej. Sportowcy muszą być doskonali w swojej dyscyplinie sportu, ale również muszą być celebrytami rozbawiającymi publiczność i podtrzymującymi zainteresowanie swoją osobą. Gwiazdorstwo sportowe staje się zatem procesem, w którym sportowi celebryci stają się coraz bardziej sławni z powodu bycia sławnymi (Boyle, Haynes 2009). Teksty o sportowcach zawierają coraz dłuższe opowieści dotyczące nie tylko spraw związanych ze sportem, ale również życia prywatnego, sensacji i skandali. Przeniknięcie wartości komercyjnych do świata sportu spowodowało, że bardzo często akcentuje się wartość ekonomiczną zawodników i ich majątek (Boyle, Haynes 2009). Medialne historie są przesiąknięte opowieściami o pieniądzach, chciwości, korupcji i oszustwach. Równie dobrze sprzedają się historie o tradycyjnych bohaterach jak o antybohaterach. Ten drugi rodzaj narracji, przedstawiający sportowców jako czarne charaktery, łamiących zasady i konwencje, ma charakter postmodernistycznego zamazywania różnicy między realnym a wirtualnym, relatywizmem, pastiszem a brakiem zgody społecznej co do odtwarzanych wartości (Berg 1998). Wielokrotnie przywoływanym przykładem takiego antybohatera-celebryty jest Dennis Rodman, amerykański koszykarz zawodowy, bohater wielu głośnych skandali.

Gwiazdorzy sportowi są obecnie inaczej opisywani również ze względu na zmiany relacji płciowych $\mathrm{w}$ społeczeństwie, czy tak zwany kryzys męskości. W przekazach medialnych dochodzi do erotyzacji wizerunków sportowców. Dbanie o wygląd zewnętrzny i eksponowanie cielesności nie jest już sprzeczne z dominującym wyobrażeniem o męskości (przykład Davida Beckhama czy Cristiano Ronaldo). Garry Whannel (2002) twierdzi jednak, że rola w mediach wzorów osobowych ze świata sportu będzie rosła bez względu na przekonania o kryzysie wartości w społeczeństwach Zachodu i o schyłku męskości/męskiej dominacji, a współczesny sport zachowa swoje miejsce w kształtowaniu dyskursów dotyczących męskości. 


\section{KONSTRUOWANIE MĘSKOŚCI W SPORTOWYCH PRZEKAZACH PRASOWYCH W „GAZECIE WYBORCZEJ” W LATACH 2010-2013}

\section{Metodologia badań}

Jaki zatem jest obraz męskości w polskim dyskursie medialnym?

Podjęliśmy próbę empirycznej odpowiedzi na to pytanie. Zasadniczym celem badania było poznanie, ile miejsca $\mathrm{w}$ prasie zajmują przekazy prasowe dotyczące sportu kobiet i mężczyzn, a także jakościowa analiza ich treści. Źródłem materiału badawczego stała się „Gazeta Wyborcza” — jako najbardziej opiniotwórczy dziennik w kraju.

Badanie objęło lata 2010-2013, tak aby analiza dotyczyła zarówno lat olimpijskich (Vancouver 2010, Londyn 2012), jak i nieolimpijskich. Pod uwagę był brany co drugi tydzień z każdego miesiąca (wydania od poniedziałku do soboty. strony sportowe i poniedziałkowy dodatek „Sport Extra”). Do analizy włączono artykuły dłuższe niż sto słów (krótsze, najczęściej zatytułowane „W skrócie”, były jedynie sprawozdaniami z wyników sportowych). Pod uwagę nie były brane felietony, ponieważ jako wyraz opinii jedynie ich autora nie spełniały standardów obiektywności. Do analizy włączono również artykułów, które nie były bezpośrednio związane z rywalizacją na arenach sportowych, dotyczyły na przykład budowy stadionów czy potencjału ekonomicznego sportu. Łącznie przeanalizowano 2997 artykułów. Analiza ilościowa polegała na sprawdzeniu, czy dany artykuł dotyczył sportu kobiet czy mężczyzn, płci autora, opisywanej dyscypliny oraz płci wypowiadającego się o sporcie autora.

Stworzono arkusz kodowania. Artykuły zakodowano ze względu na ich długość (decydowała liczba słów), płeć autora tekstu, dyscyplinę sportu oraz rodzaj dyscypliny: indywidualna oraz zespołowa. Druga część narzędzia, przeznaczona do analizy jakościowej, zawierała cztery kategorie kodowania: wygląd zewnętrzy i seksualność sportowców (podkreślanie urody, ubioru, atletyczności, muskulatury czy heteroseksualności zawodników przez odwołania do ich związków z kobietami, aktywności seksualnej itp.), podkreślanie stereotypowych wersji męskości (opisywanie mężczyzn jako „urodzonych do sportu”, wytrzymałych i silnych fizycznie, zachowujących się w sposób ryzykowny i brawurowy), język oraz komentarze (użycie metafor wojennych, komentarzy wychwalających sportowców, ale również sarkazmu i ironii). Ostatnią kategorią było opisywanie sukcesów i porażek (koncentrowanie się w artykułach na słabych występach, porażkach czy sukcesach zawodników, sposobie tłumaczenia porażek i zwycięstw).

Przed badaniem głównym przeprowadzono badanie pilotażowe, aby sprawdzić zgodność kodowania danych przez poszczególnych badaczy. Zbadano 400 artykułów, co stanowi 13,3\% próby badawczej. Z badania pilotażowego wynika, iż osiągnęto zgodność w analizowaniu na poziomie $96 \%$. Pozostała 
część próby badawczej została losowo przydzielona każdemu z badaczy. Każdy artkuł został przeanalizowany dwukrotnie.

\section{Analiza ilościowa}

Z przeanalizowanych 2997 artykułów sportu mężczyzn dotyczyło aż 2610. W żadnym z przebadanych lat odsetek artykułów na temat sportu mężczyzn nie był niższy niż $81 \%$ (tabela 1). Potwierdziło się zatem przypuszczenie, iż sport mężczyzn uważany jest za najistotniejszy komponent sportu w ogóle, pewien wzór. Również charakterystyka opisywanych w przekazach prasowych dyscyplin $\mathrm{w}$ perspektywie płciowej odpowiada obrazowi zarysowanemu na podstawie analizy literatury przedmiotu. W artykułach na temat mężczyzn zdecydowanie przeważają relacje ze sportów zespołowych. Odpowiada to przekonaniu, że sporty kobiece to głównie sporty indywidualne, natomiast sporty męskie to sporty zespołowe (Riemer, Visio 2003). Ponad 50\% wszystkich artykułów dotyczących mężczyzn zawierało relacje dotyczące rywalizacji w piłce nożnej. W 2013 roku udział artykułów o tej dyscyplinie sięgnął blisko 60\%. Pokazuje to, że piłka nożna nadal stanowi instytucjonalny rdzeń sportu w Europie, a tym samym bastion męskości (Giulianotti 1999).

Tabela 1

Przekazy prasowe o sporcie męskim i kobiecym, „Gazeta Wyborcza”, lata 2010-2013 (w \%)

\begin{tabular}{|l|c|c|c|c|c|c|c|c|}
\hline \multirow{2}{*}{ Lata } & \multicolumn{2}{|c|}{2010} & \multicolumn{2}{c|}{2011} & \multicolumn{2}{c|}{2012} & \multicolumn{2}{c|}{2013} \\
\cline { 2 - 10 } & $\begin{array}{c}\text { męż- } \\
\text { czyźni } \\
\mathrm{N}=893\end{array}$ & $\begin{array}{c}\text { kobiety } \\
\mathrm{N}=117\end{array}$ & $\begin{array}{c}\text { męż- } \\
\text { czyźni } \\
\mathrm{N}=732\end{array}$ & $\begin{array}{c}\text { kobiety } \\
\mathrm{N}=94\end{array}$ & $\begin{array}{c}\text { męż- } \\
\text { czyźni } \\
\mathrm{N}=514\end{array}$ & $\begin{array}{c}\text { kobiety } \\
\mathrm{N}=97\end{array}$ & $\begin{array}{c}\text { męż- } \\
\text { czyźni } \\
\mathrm{N}=471\end{array}$ & $\begin{array}{c}\text { kobiety } \\
\mathrm{N}=79\end{array}$ \\
\hline powyżej 550 słów & 34 & 30 & 39 & 43 & 50 & 48 & 21 & 30 \\
od 200 do 550 słów & 57 & 59 & 49 & 52 & 45 & 42 & 68 & 52 \\
poniżej 200 słów & 9 & 11 & 12 & 5 & 5 & 10 & 11 & 18 \\
\hline Ogółem & 87 & 11 & 86 & 11 & 81 & 15 & 81 & 14 \\
\hline
\end{tabular}

Jeśli chodzi o sporty indywidualne, to w żadnym $\mathrm{z}$ analizowanych lat liczba artykułów nie przekroczyła 7\%. Wyróżnia się liczba relacji dotyczących boksu, tenisa, sportów motorowych, kolarstwa, lekkoatletyki oraz skoków narciarskich. Skoki narciarskie przez uznanie dla sukcesów Adama Małysza nadal są dyscypliną bardzo popularną w Polsce. Stosunkowo duża liczba przekazów na temat sportów motorowych to w dużej mierze obszerne relacje dotyczące ciężkiego wypadku, któremu w 2010 roku uległ Robert Kubica, kierowca formuły 1. Boks, podobnie jak koszykówka i piłka ręczna, są uważane za sporty kontaktowe bądź kolizyjne i tradycyjnie kojarzy się je z męskością. Również siatkówka często pojawiała się na łamach gazety. Chociaż badania pokazują, iż coraz częściej uchodzi za sport neutralny płciowo, to jako sport drużynowy pozwala na 
identyfikowanie się fanów z zespołem, zapewniając dużą dawkę emocji i poczucie wspólnoty (Riemer, Visio 2003). Żaden z badanych artykułów nie traktował o uczestnictwie mężczyzn w sportach uważanych za kobiece.

Badanie potwierdziło również, że tworzeniem sportowych przekazów medialnych zajmują się głównie mężczyźni ${ }^{3}$. Przy tworzeniu materiałów sportowych do „Gazety Wyborczej” brało udział aż 108 dziennikarzy. Jedynie 11 artykułów z 2997 zostało napisanych przez kobiety (pięć dziennikarek). Przeanalizowano również płeć ekspertów, z którymi przeprowadzono rozmowy na łamach sportowych stron dziennika. Zazwyczaj byli to naukowcy, politycy czy działacze sprawujący pieczę nad sportem w Polsce lub uznani trenerzy w danej dyscyplinie sportu. Z 279 takich artykułów jedynie 16 nie dotyczyło opinii mężczyzn na dyskutowany temat. Przewagę męskiej wiedzy eksperckiej należy łączyć z generalnym przeświadczeniem, iż sport w ogóle jest męskim przedsięwzięciem.

\section{Analiza jakościowa dotycząca sportu mężczyzn}

Czy i w jaki sposób dziennikarze odnoszą się do wyglądu fizycznego i seksualności zawodników? Opisywany jest wzrost czy masa ciała mężczyzn, ale również muskulatura, która ma symbolizować siłę i wytrzymałość. Charakterystyka fizyczności wiązana jest z szansami na odniesienie sukcesu $\mathrm{w}$ danej dyscyplinie.

"Zasięg i siła, to potężne atuty mającego 205 cm wzrostu Kurka” [24.06.2013].

„Wykorzystującego bezlitośnie nadzwyczajne atuty fizyczne: ponad dwumetrowy zasięg ramion, dzięki którem kontroluje rywala przeraźliwie długim lewym prostym; 110 kilogramów wagi, dzięki którym wyczerpuje przeciwnika, gdy dochodzi do zapasów w zwarciu; arcysprawność w poruszaniu się, dzięki której jest $\mathrm{w}$ stanie wybrać idealne miejsce i moment ataku, niezwykłą siłę ciosu, dzięki której znokautował 80\% przeciwników" [o Floydzie Mayweatherze: 7.10.2913].

Koncentracja na atletyzmie i niezwykłych możliwościach fizycznych na pewno jest powiązana z postrzeganiem męskości jako fizycznej siły. Zgodnie $z$ twierdzeniem Sabo i Jansen, sportowców przedstawiano również jako osoby posiadające ponadnaturalne zdolności:

„Maicon stracił ząb i opuszczał murawę na noszach. Diega Milito trzeba było zdjać na kwadrans przed końcem, bo nie mógł ustać na nogach. Zwyczajni śmiertelnicy dla własnego bezpieczeństwa nie powinni sobie nawet wyobrażać, ile życiowych mocy wysysają z piłkarzy - nawet tych najbardziej cyborgowatych w ruchach - takie wieczory. W Pekinie Amerykanin (Phelps) dokonał czegoś przełomowego — zdobył osiem złotych medali, pobił Marka Spitza. Było to

${ }^{3}$ Znaczna większość artykułów była podpisana imieniem i nazwiskiem, co pozwoliło rozpoznać płeć autora. W przypadku posługiwania się inicjałami odpowiednich informacji dostarczył dział sportowy gazety. 
nadzwyczajne dokonanie w sferze fizycznej, pękła kolejna granica możliwości ludzkiego organizmu" [27.07.2012].

Sportowców charakteryzuje się jako „superbohaterów”, „bogów” czy „roboty”, ale również jako postaci baśniowe: „smoki”, „czarodziejów” lub „potwory".

Podkreśla się zdecydowanie heteroseksualność sportowców. Zwłaszcza w artykułach o piłkarzach można było wyczytać, z kim się aktualnie spotykają i z iloma kobietami żyli. Popularne WAGs (wives and girlfriends) nie moga jednak liczyć na rzetelny opis. Charakteryzuje się je ze względu na urodę i traktuje z lekceważeniem.

„W 2009 roku Gatti pojechał do Brazylii na ślub swojej siostry. Towarzyszyła mu piękna żona, 23-letnia była brazylijska striptizerka Amanda Rodrigues, oraz ich 10-miesięczny syn" [17.12.2012].

$\mathrm{Z}$ analizowanego materiału wynika również, że dziennikarze „Gazety Wyborczej" starali się podtrzymać obraz sportowców jako mężczyzn aktywnych seksualnie. Wydarzenia sportowe przeplatano opowieściami o skandalach ujawniających nocne libacje, małżeńskie zdrady i korzystanie $z$ usług prostytutek.

„Włoscy trenerzy nie przyzwyczaili się do mediów po drugiej stronie kanału La Manche. Od tygodni są pytani o Terry'ego, który miał romans z matką dziecka Bridge'a [...]. Terry miał ostatnio chwilę oddechu, bo gazety rzuciły się na jego klubowego kolegę Ashleya Cole’a. 30-letni obrońca zdradzał żonę z pięcioma kobietami (liczba każdego dnia wzrasta), jednej z nich wysyłał zdjęcia w bieliźnie, inną przemycał na zgrupowania i uprawiał z nią seks przed meczami” [1.03. 2013].

„Potem poznał siatkarkę plażową Morgan Beck, która dała mu kosza na pierwszej, drugiej i trzeciej randce, ale on atakował do skutku. Po dwóch miesiącach wzięli ślub. Niedługo potem Millerowi urodził się syn, ale nie ze związku z Morgan, ale $z$ poprzedniego $-z$ Sarą McKenna. O prawo do opieki musiał stoczyć $z$ byłą partnerką batalię w sądzie. To drugie dziecko Millera, bo w Kalifornii mieszka 5-letnia córka z jeszcze innego związku" [25.10.2013].

Szczególnie często przedmiotem relacji stawały się zdrady Rooneya, Woodsa i problemy z prawem Ribéry'ego spowodowane kontaktami z nieletnią prostytutką. Wydarzeń tych nie wiązano jednak z strukturą organizacji sportu, wartościami oraz normami, które ona podtrzymuje. Należy zaznaczyć, iż nie napotkano artykułu, w którym akcentowano by homoseksualność zawodników.

Charakterystyka męskości opierała się na tradycyjnych treściach dotyczących zaciętości czy waleczności sportowców.

„To najświetniejszy obrońca wśród napastników, brutal gotowy zagryźć każdego, kogo dopadnie. Idealny kandydat by dać w twarz sforze wściekłych psów z Atlético - drużynie zdeterminowanych, agresywnych, przykrych w bliskim kontakcie wojowników, którzy zachowują się tak, jak wielogłowe wcielenie trenera Diego 
Simeone, niegdyś twardziela nad twardzielami wśród boiskowych bandytów" [10.10.2013].

Mężczyzn opisywano jako dających z siebie wszystko i zdolnych do ogromnych poświęceń. Tych cech nie akcentowano przy opisach kobiet w sporcie. Dlatego też sporo miejsca poświęcano kontuzjom zawodników, dokładnie je analizując.

„W drugiej walce Kanadyjczyk wygrał mimo złamania ręki już w czwartej rundzie, wcześniej ta sama ręka dwukrotnie była operowana. W każdym pojedynku z Wardem Gatti kilkakrotnie był bliski utraty świadomości, był na skraju, a jednak podrywał się — i dwukrotnie wygrał" [17.12.2012].

„Kolana odmawiają posłuszeństwa, bolą, puchną, trzeba w nie wbijać igły, pompować komórki macierzyste, co boli koszmarnie, przeszły już po dwie operacje. Kręgosłup też wymaga pielęgnacji, nie dalszego niszczenia, przyjmuje 30 blokad na sezon, a lekarz dostaje drgawek, gdy widzi na ekranie telefonu, że dzwoni Dołęga. Przypomnijmy: do Pekinu Dołęga jechał jako pewniak do złota, ale nabawił się kontuzji nogi, ledwo kuśtykał, wył z bólu - przed wyjazdem wziął 30 zastrzyków blokad. Z nieludzkim cierpieniem wymalowanym na twarzy przegrał brązowy medal z Łapikowem o 70 g." [7.08.2012].

Wywiad z Jarosławem Krzywańskim, lekarzem sportowym, zastępcą szefa komisji medycznej PKOl, zatytułowany Chcesz wygrać, bądź gotów na wielki ból [10.08.2012], ilustruje przekonanie, że ból jest niezbędną częścią składową współczesnego sportu. Przykładem może być również najpierw codzienne informowanie o stanie zdrowia polskiego kierowcy Roberta Kubicy po bardzo groźnym wypadku, a następnie systematyczne relacje $z$ jego walki o powrót do sportu. Wielu ekspertów na łamach gazety dowodziło, ile poświęcenia i determinacji kosztowała go rehabilitacja chorej ręki, a potem zmiana fotela kierowcy formuły 1 na samochód WRC. Przedstawienia mężczyzn jako negujących ból i przezwyciężających swoje słabości wzmacniane było metaforami wojennymi. Materiały na temat sportowców były nimi przeładowane. Sugerowały zawsze bardzo poważny charakter męskiej pracy i zaangażowanie wszystkich możliwych środków. Dlatego mężczyźni to „terminatorzy”, „gladiatorzy”, „dominatorzy”, „hegemoni” czy „cesarze”, którzy „ścierają się na wojnie” oraz „walczą na śmierć i życie". Opisy takie nie pozostawiają wątpliwości, iż reprezentują oni w sporcie najwyższy stopień zaangażowania.

„Po latach starć przed kamerami i boiskowych awantur kończonych wkładaniem palców w oczy rywali wojna w EL Clasico się skończyła" [19.08.2013].

Wiele miejsca $\mathrm{w}$ artykułach o sporcie zajęły również kwestie pieniędzy za transfery, dochodów poszczególnych klubów piłkarskich czy korzyści, które daje sport. Informacje, ile „wart” jest określony piłkarz, czy ile zarobił w sporcie, zajmowały poczesne miejsce $\mathrm{w}$ większości analizowanego materiału. Również takie informacje można interpretować jako potwierdzenie „wielkości” sportowców. Ogromne kwoty, które kluby płaciły za transfery, bez wątpienia wywołuja 
wrażenie, iż mówimy o najlepszych z najlepszych. Oczywiście wymiar ekonomiczny sportu kobiet jest trudniejszy do uchwycenia, ponieważ piłka nożna kobiet oraz pozostałe dyscypliny drużynowe nie są tak popularne. Przy opisie najbardziej znanych tenisistek kwestia zarobionych na korcie pieniędzy również się pojawiała, jednak nie była tak uwypuklana jak w przypadku mężczyzn. Wielkie zarobki męskich gwiazd sportu odzwierciedlał przede wszystkim ich status w mediach. Zarabiając więcej na kontraktach reklamowych niż uprawianiu sportu pokazywali, że są rozpoznawani na całym świecie i tworzą niepowtarzalną „markę” (Boyle, Haynes 2009).

„Bolt był wszędzie, tu pozował z gepardem, tam z panda, tu na reklamie ścigał go jakiś człowiek z kartą kredytową, tam reklamował szybki Internet, tu promował gry na komórkę, tam autobiografię" [27.07.2012].

Kolejną taktyką przywoływaną w celu uprawomocnienia determinacji opisywanych bohaterów było odwoływanie się do trudnej drogi do sportu. Często relacjonowano dorastanie $\mathrm{w}$ biedzie, trudne warunki życia i przeszkody, jakie musieli pokonać, aby sportowy świat się na nich poznał.

„Zielińscy, zaczynając, nad głowę zamiast sztangi podnosili kij od miotły. Gryf waży $20 \mathrm{~kg}$, o wiele za dużo dla dziecka. Warunki były spartańskie. Pierwszy budynek zawalił się od ciężarów. Przerzucanie żelastwa miłe dla uszu nie jest. Hałas jest okropny, dlatego z kolejnej siedziby przegonili zawodników mieszkańcy. Później była hydrofornia koło dworca PKP, gdzie zimą zamarzała woda" (o mistrzu olimpijskim w podnoszeniu ciężarów Adrianie Zielińskim i jego bracie Tomaszu [6.08.2012]).

Za takiego rodzaju opisem kryje się przekonanie, że sport mężczyzn jest działalnością dla wybranych, garstki najlepszych na świecie, gdyż trzeba poświęcić naprawdę wiele, aby znaleźć swoje miejsce.

Innym tradycyjnym sposobem przedstawienia męskości było opisywanie awantur i bijatyk, w których uczestniczyli sportowcy. Informowano również o przypadkach przemocy wobec kobiet, której się dopuszczali (Lilian Thuram, Floyd Mayweather, Mike Tayson; opisów tych nie poddano gruntownej analizie, nie zajmowano się bowiem problemem przemocy w sporcie). Przywoływanie agresywnego zachowania ma podtrzymywać przekonanie o tym, że agresja jest „męska” i do męskości przynależy.

„Na razie szaleje poza boiskiem. W sobotę włoskie media doniosły o bijatyce, w jaką wdał się w nocnym klubie. To nie pierwszy taki wyskok w karierze byłego piłkarza Chelsea i Juventusu, ale, jak powiedział dyrektor klubu Andrea Della Valle, nigdy wcześniej sprawa nie wyglądała na tak poważną. W oświadczeniu klub oznajmił, że czeka na wyniki policyjnego śledztwa. Nieoficjalnie mówi się, że jeśli zarzuty się potwierdzą, recydywista zostanie surowo ukarany" [22.12.2010].

„Remis z Nową Zelandią i porażka z Paragwajem rodaków rozeźliły, kadrę paraliżuje rosnące napięcie, trener Vladimir Weiss już nie rozmawia z dzienni- 
karzami, bo jednego z nich wulgarnie zwyzywał i zagroził, że da mu w twarz" [24.06.2010].

Kolejny przedmiot analiz to język przekazów. Często były stosowane metafory wojenne (,żołnierze”, „komandosi”, „snajperzy”), które podtrzymywały przekaz, że sport mężczyzn jest śmiertelnie poważnym zajęciem, a mężczyźni to bohaterowie narodowi walczący w imię wyższych celów. Ponadto posługiwano się często ironią i sarkazmem. Surowo oceniano sportowców, którzy zawiedli, zwłaszcza piłkarzy. Można ocenić taki sposób komentowania poczynań sportowców jako „traktowanie ich po męsku”, szorstko, bez ogródek. Jednoznaczne ocenianie poczynań sportowców różni się od sposobu relacji sportu kobiet. W sporcie kobiet częściej dawano „taryfę ulgową”, mężczyźni natomiast traktowani byli „po męsku”.

„Na razie drużyna, która ma wygrywać na Euro, przypomina wielki plac budowy. Fundamentów nie widać, panuje bałagan, a główny architekt sam do końca nie wie, co $z$ jego koncepcji powstanie" (o polskiej reprezentacji w piłce nożnej [11.08.2010]).

Zniuansowany pozostaje obraz sportu mężczyzn z perspektywy porażek i sukcesów. W „Gazecie Wyborczej” pisze się bowiem o sporcie mężczyzn niezależnie od ich dokonań. Dotyczy to przede wszystkim polskiej ligi piłki nożnej, której poziom nie jest najwyższy. Informacja o danym meczu czy turnieju nie musi dotyczyć ważnych dokonań czy wyników, aby pojawiła się na stronie gazety. Można odnieść wrażenie, że relacjonuje się te wydarzenia ze względu na przekonanie, że sport to męska rzecz. Sportowców mimo wszystko przedstawia się jako aktywnych, biorących sprawy w swoje ręce, często wiele ryzykujących, aby odnieść w sporcie sukces. Ich sukces sportowy zależy od nich. Nie akcentowano roli innych osób, które sportowcami miałyby kierować. Jest to zasadnicza różnica $\mathrm{w}$ porównaniu $\mathrm{z}$ opisem sportu kobiet. Sukces w sporcie kobiet często przypisuje się roli trenera czy rodzica bądź innym czynnikom zewnętrznym.

Należy zwrócić uwagę, że na łamach „Gazety Wyborczej” dostrzegalna jest tendencja do przedstawiania sportowców jako celebrytów. W poniedziałkowej rozbudowanej sekcji sportowej dziennika poświęcano im długie artykuły, przedstawiające nie tylko osiągnięcia $\mathrm{w}$ sporcie, ale również życie prywatne, drogę dojścia do sławy i wiele informacji o nich bezpośrednio niezwiązanych ze sportem. Okazało się też, że gwiazdorstwo sportowe w prasowych opisach było udziałem sportowców, ale nie sportowczyń.

„Narciarska kariera Bode Millera po operacji kolana nieco zwolniła, ale jego życie wciąż pędzi. Właśnie wziął ślub z dziewczyną z plakatu. Świadkiem był kot, a jego wyścigowy koń Carving wygrał gonitwę w Hollywood. Człowiek, który wychował się w lasach New Hampshire w rodzinie hipisów w domku bez elektryczności, a potem - pijąc po drodze dużo tequili — został najwybitniejszym narciarzem USA w historii, wciąż nie daje o sobie zapomnieć, choć od dawna niczego nie wygrał" [29.11.2012]. 
Potwierdza się teza Whennela, że w przekazach sportowych dominuje wątek gwiazdorstwa sportowego. Akcent przesuwa się z informacji o walce sportowej na wiadomości okołosportowe.

Przedstawione wyniki badań prasowych przekazów sportowych pokazują, iż informacje medialne są upłciowione. W artykułach „Gazety Wyborczej” podtrzymywano tradycyjny sposób konstruowania męskości.

Zwraca uwagę znacząca przewaga artykułów dotyczących sportu mężczyzn oraz dziennikarzy i ekspertów płci męskiej. Analiza jakościowa potwierdziła, że sposób charakteryzowania męskości jest zgodny z opisem męskości hegemonicznej Reawyn Connell. Wiele miejsca poświęcano opisom sportowej doskonałości i atletyzmu zawodników. Akcentowano ich heteroseksualizm i aktywność seksualną. Zwracając uwagę na ich zarobki i wartość rynkową, potwierdzano ich wielkość oraz status gwiazdy.

Tezę, że sport mężczyzn jest poważną kwestią, potwierdzano również w warstwie językowej za pomocą metafor wojennych. Zdecydowana przewaga informacji o sportach drużynowych dawała możliwość podtrzymywania emocjonalnej identyfikacji fanów z drużyną, co czyni sportowców idealnymi nosicielami wartości narodowych oraz powoduje, że stają się ikonami popkultury. Prasowe opisy doskonale wpisują się w schemat gwiazdorstwa sportowego. $\mathrm{Z}$ uwagi na akcentowanie heteroseksualności zawodników, ich atutów fizycznych oraz język wypowiedzi prasowych należy uznać, że uczestniczą one w odtwarzaniu męskości hegemonicznej. W analizowanych materiałach „Gazety Wyborczej" nie zauważono komentarzy podważających dominujący dyskurs męskości.

Zastosowanie podejścia krytycznego pozwala zauważyć, iż sport jest instytucją upłciowioną, która odtwarza określone wzorce kobiecości i męskości. Jednocześnie upowszechnienie kategorii płci kulturowej — i użycie jej w badaniach dotyczących nie tylko kobiet, ale i mężczyzn — spowodowało, że męskość przestała być uważana za oczywistą, a sam sport zaczęto postrzegać jako instytucję zorganizowaną wokół dominującej formy męskości (Messner 1992). Obecnie, sport i media są od siebie wzajemnie zależne, co ujmuje neologizm mediasport (czy terminy takie jak: media/sport production complex lub the media sports cultural complex (Rowe 2004; Messner 1992). Zwraca się uwagę, iż symboliczna władza mediasport jest znacznie większa niż niegdyś oddzielnie jej składowych: sportu i konsumpcji medialnej. Technologie komunikacyjne pozwoliły przekazom sportowym osiągnąć niemożliwy wcześniej zasięg i wpływać na większość aspektów życia społecznego. Wielkie wydarzenia sportowe w rodzaju Igrzysk 
Olimpijskich czy Super Bowl kształtują wyobraźnię większości ludzi na świecie, cementując przejście od tradycyjnych wartości związanych ze sportem do kultury konsumenckiej późnego kapitalizmu (Real 1998). Ze względu na rolę sponsorów i reklamodawców mediasport bez zarzutów wpasowuje się w potrzeby rynku, co ostatecznie powoduje dominację w kreowaniu wzorów i kulturowych znaczeń powiązanych ze sportem (Wenner 2015). Zapośredniczenie sportu przez produkcję medialną jest równocześnie źródłem dobrze opisanych w literaturze problemów współczesnego sportu, takich jak korporacjonizacja, utowarowienie, eksploatacja, przemoc czy wzmacnianie dominujących w kulturze ideologii i władzy chociażby w zakresie naturalizowania oraz różnicowania kategorii rasy czy płci (Wenner 2015; Real 1998).

\section{BIBLIOGRAFIA}

Adams Adi, 2011, 'Josh Wears Pink Cleats': Inclusive Masculinity on the Soccer Field, ,Journal of Homosexuality", t. 58(5), s. 579-596.

Adams Adi, Anderson Eric, McCormack Mark, 2010, Establishing and Challenging Masculinity: The Influence of Gendered Discourses in Organized Sport, „Journal of Language and Social Psychology”, t. 29(3), s. 278-300.

Anderson Eric, 2005, In the Game: Gay Athletes and the Cult of the Masculinity, State University of New York Press, New York.

Anderson Eric, 2008, 'I Used to Think that Women Are Weak': Orthodox Masculinity, Gender Segregation and Sport, „Sociological Forum”, t. 23(2), s. 257-280.

Anderson Eric, 2009, The Maintenance of Masculinity Among the Stakeholders of Sport, „Sport Management Review", t. 12, s. 3-14.

Anderson Eric, 2011, Masculinities and Sexualities in Sport and Physical Cultures: Three Decades of Evolving Research, „Journal of Homosexuality”, t. 58(5), s. 565-578.

Anderson Eric, 2012, Shifting Masculinities in Anglo-American Countries, „Masculinities and Social Change", t. 1(1), s. 40-60.

Anderson Eric, Mcguire Rhidian, 2010, Inclusive Masculinity Theory and Gendered Politics of Men's Rugby, „Journal of Gender Studies”, t. (19)3, s. 249-261.

Berg Leah, 1998, The Sport Hero Meets Mediated Celebrityhood, w: Lawrence Wenner (red.), Mediasport, Routledge, London-New York.

Bishop Ronald, 2003, Missing in Action: Feature Coverage of Women's Sport in Sport Illustreted, „Journal of Sport and Social Issues", t. 27, s. 184-194.

Boyle Raymond, Haynes Richard, 2009, Power Play: Sport, the Media and Popular Culture, Edinburgh University Press, Edinburgh.

Capranica Laura i in., 2005, Newspaper Coverage of Women's Sport During The 2000 Sydney Olympic Games: Belgium, Denmark, France and Italy, „Research Quarterly for Exercise and Sport”, t. 76, s. 212-223.

Chimot Caroline, Louveau Catherine, 2010, Becoming a Man While Playing a Female Sport: The Construction of Masculine Identity in Boys Doing Rhythmic Gymnastics, „International Review for the Sociology of Sport", t. 45(4), s. 436-456.

Connell Raewyn W., 2001, Masculinities, Polity Press, Cambridge.

Connell Raewyn W., 2000, Men and the Boys, University of California Press, Berkeley.

Connell Raewyn W., 1998, Gender and Power: Society, the Person and Sexual Politics, Polity Press, Cambridge. 
Coston Bethany, Kimmel Michael, 2012, Seeing Privilege Where It Isn't: Marginalized Masculinities and the Intersectionality of Privilege, ,Journal of Social Issues”, t. 68(1), s. 97-111.

Crosset Tod, 1989, Masculinity, Sexuality and the Development of Early Modern Sport, w: Michel Messner, Donald F. Sabo (red.), Sport, Men and the Gender Order, Human Kinetics, Champaign, Il.

Giulianotti Richard, 1999, Football: A Sociology of the Global Game, Polity, Cambridge.

Gove Jeremy P., 2012, Three and Out: The NFL's Concussion Liability and How Players Can Tackle the Problem, „Journal of Entertainment and Technology Law", t. 14(3), s. 649-691.

Guccione John, 2014, Moving Past a 'Pocket Change' Settlement: The Threat of Preemption and How the Loss of Chance Doctrine Can Help NFL Concussion Plaintiffs Prove Causation, "Journal of Law and Policy”, t. 22(2), s. 907-956.

Grindstaff Laura, West Emilly, 2006, Cheerleading and the Gendered Politics of Sport, „Social Problems”, t. 53(4), s. 500-518.

Hall Stuart, 1987, Kodowanie i dekodowanie, „Przekazy i Opinie”, nr 1-2.

Harris John Clayton Ben, 2002, Femininity, Masculinity, Physicality and the English Tabloid Press, „International Review for the Sociology of Sport", t. 37, s. 397-413.

Hasbrook Cynthia, Harris Othello, 2006, Wrestling With Gender, w: Jim Mckay, Michael Messner, Don Sabo (red.), Masculinities, Gender Relations and Sport, Sage Publications, London.

Jakubowska Honorata, 2013, Stadion z perspektywy płci, w: Radosław Kossakowski, Krzysztof Stachura, Anna Strzałkowska, Magdalena Żadkowska (red.), Futbol i cała reszta, Wydawnictwo Orbis Exterior, Pszczółki.

Jones Amy, Greer Jennifer, 2011, You Don't Look Like an Athlete: The Effects of Feminine Appearance on Audience Perceptions of Female Athletes and Women's Sports, ,Journal of Sport Behaviour”, t. 34(4), s. 358-377.

Kaufman Michael (red.), 1987, Beyond Patriarchy: Essays by Men on Pleasure, Power, and Change, Oxford University Press, Toronto-New York.

Kidd Bruce, 1989, The Men's Cultural Centre: Sports and the Dynamics of Women's Oppression/Men's Repression, w: Michael Messner, Donald F. Sabo (red.), Sport, Men and the Gender Order, Human Kinetics, Champaign.

Kimmel Michael Scott, 1989, Baseball and the Reconstruction of American Masculinity, 1880-1920, w: Michael Messner, Donald F. Sabo (red.), Sport, Men and the Gender Order, Human Kinetics, Champaign.

Kimmel Michael Scott, 2009, Guyland: The Perilous World Where Boys Become Men, Harper, New York.

Lippe Gerd, von der, 2002, Media Image - Sport, Gender and National Identities in Five European Countries, „International Review for the Sociology of Sport”, t. 37(4), s. 371-395.

McKay Jim, Messner Michael, Sabo Don (red.), 2000, Masculinities, Gender Relations, and Sport, Sage Publications, Thousand Oaks.

Mcquail Denis, 2007, Teoria komunikowania masowego, tłum. Alina Szulżycka, Marta Bucholc, Wydawnictwo Naukowe PWN, Warszawa.

Messner Michael, 1992, Power at Play: Sport and the Problem of Masculinity, Beacon Press, Boston.

Messner Michael, Cooky Cheryl, 2010, Gender in Televised Sports: News and Highlights Shows, 1989-2010, University of Southern California Center for Feminist Research (http://dornsifecms.usc.edu/assets/sites/80/docs/tvsports.pdf [20.03.2016]).

Messner Michael, Dworkin Shari, 2002, Just Do What? Sport, Bodies, Gender, w: Sheila Scraton, Ann Flintoff (red.), Sport and Gender. A Reader, Routledge, New York.

Messner Michael, Montez de Oca Jeffrey, 2005, The Male Consumer as Loser: Beer and Liquor Ads in Mega Sports Media Events, „Signs: Journal of Women in Culture and Society”, t. 30, s. 1879-1909.

Messner Michael, Sabo Don F., 1994, Sex, Violence and Power in Sport, Rethinking Masculinity, Crossing Press, New York. 
Nadelhaft Matthew, 1993, Metawar: Sports and the Persian Gulf War, „Journal of American Culture”, t. 16(4), s. 25-33.

Real Michael, 1998, Mediasport: Technology and the Commodification of Postmodern World, w: Lawrence Wenner (red.), Mediasport, Routledge, New York.

Riemer Brenda, Visio Michelle, 2003, Gender Typing of Sports: An Investigation of Metheny's Classification, „Research Quarterly for Exercise and Sport”, t. 74, s. 193-204.

Rowe David, 2004, Sport, Culture and the Media, Open University Press, Berkshire.

Sabo Don F., Jansen Sue, 1998, Prometheus Unbound: Constructions of Masculinity in Sports Media, w: Lawrence Wenner (red.), Mediasport, Routledge, London-New York.

Theberge Nancy, Cronk Alan, 1994, Work Routines in Newspaper Sport Departments and the Coverage of Women's Sports, w: Susan Birrell, Cheryl L. Cole (red.), Women, Sport and Culture, Human Kinetics, Champaign, Il.

Wenner Lawrence, 2015, Assessing the Sociology of Sport: On the Mediasport Interpellation and Commodity Narratives, „International Review for the Sociology of Sport”, t. 50(3-4), s. 628-633.

Whannel Garry, 2002, Media Sport Stars: Masculinities and Moralities, Routledge, London-New York. Whitson David, 1989, Sport in the Social Construction of Masculinity, w: Michael Messner, Donald F. Sabo (red.), Sport, Men and the Gender Order, Human Kinetics, Champaign.

Whitson David, 2002, The Embodiment of Gender: Discipline, Domination, and Empowerment, w: Susan Scraton, Anne Flintoff (red.), Sport and Gender. A Reader, Routledge, New York.

\section{ON MASCULINITY AS CONSTRUCTED BY THE MEDIA: AN OUTLINE OF THEORETICAL ISSUES AND AN EXAMPLE OF AN EMPIRICAL ANALYSIS}

\section{Summary}

This article analyzes how the category of masculinity is constructed in sports writing. It uses texts on sports that appeared in Gazeta Wyborcza, an opinion-forming Polish newspaper. The number of such articles was calculated, with distinctions between men's and women's sports, and the gender of the journalists or experts involved. Qualitative analysis showed which disciplines are presented and in what manner, and how the roles of male and female participants are characterized. It emerges that the media message varies in regard to the type of sport and manner of describing the participants. It is shown that the texts in Gazeta Wyborcza reproduce hegemonic masculinity.

\section{Key words / słowa kluczowe}

gender, masculinity / męskość, sport, content analysis / analiza treści, Gazeta Wyborcza newspaper / dziennik „Gazeta Wyborcza” 